\title{
Redes sociales para crear conciencia social de género. El caso del Museo de Bellas Artes de Sevilla
}

Lourdes Páez Morales | Departamento de Conservación e Investigación del Museo de Bellas Artes de Sevilla

URL de la contribución <www.iaph.es/revistaph/index.php/revistaph/article/view/3702>

Desde que comenzamos nuestra andadura en las redes sociales a finales de 2012, en el Museo de Bellas Artes de Sevilla tuvimos claro que estas $-y$ entre ellas fundamentalmente la página de Facebook- eran, además de un medio que nos posibilitaba llegar a más personas permitiéndonos una comunicación más directa con nuestro público virtual y real, un foro ideal para crear conciencia social desde la institución, difundiendo ciertos valores que consideramos fundamentales en la sociedad actual: la igualdad entre sexos, la investigación de ciertas enfermedades, como el cáncer o el alzheimer, que nos tocan muy de cerca a casi todos, o la defensa de los animales, entre otros.

Para ello debíamos hacer una relectura de las obras de nuestra colección que nos permitiese tratar de estos temas, con ella como hilo conductor. Uno de esos argumentos, quizá el más complejo de abordar, era el de la igualdad de géneros, que podía crear suspicacias entre algunos seguidores de nuestra página, o nos podía restar audiencia. No obstante consideramos que era un riesgo necesario que teníamos que asumir, para dar normalidad a esta legítima reivindicación.

Ante nosotros se abría un reto emocionante: dar voz y poner nombre a muchas mujeres que hasta ahora habían pasado desapercibidas como piezas secundarias del engranaje artístico a lo largo de los casi dos siglos de existencia de la institución. Eran modelos de artistas; mujeres retratadas de las que no se conocía nombre ni apellidos, que después de décadas habían pasado a ser llamadas simplemente "la señora de"; donantes y esposas de artistas que habían sido parte importante de la conformación del museo, pero que habían quedado eclipsadas por sus padres, maridos o retratistas. Todas ellas, mediante una investigación rigurosa, iban a salir de nuevo a la luz.

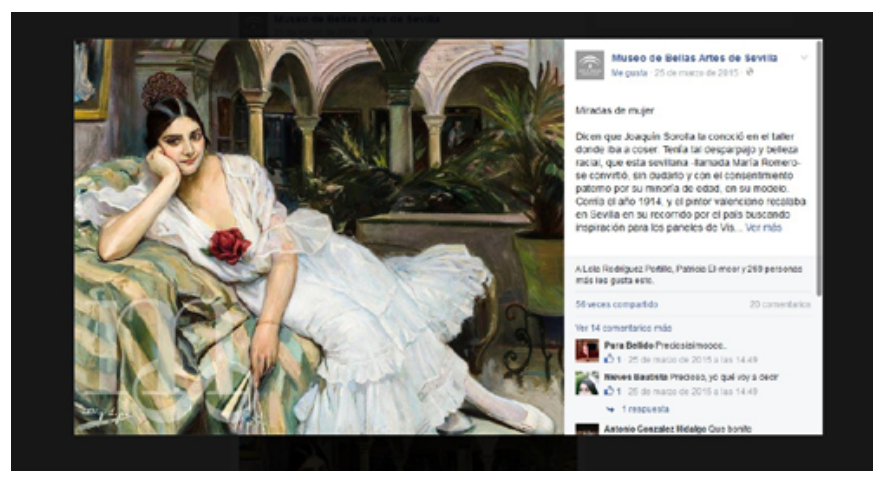

Miradas de mujer: María la guapa | perfil de Facebook del Museo de Bellas Artes de Sevilla, para todas las imágenes de la contribución

Desde los inicios decidimos crear una sección titulada "Miradas de mujer", donde contaríamos a nuestros seguidores historias emocionantes, como la de María la guapa, modelo descubierta en Sevilla por Sorolla, que acabó siendo musa también de otros pintores, como el sevillano Diego López, que la retrata en una de sus mejores obras, titulada Sevillana en su patio, que fue donada al Museo en el año 1995.

Gracias a esta publicación, familiares aún cercanos de María se pusieron en contacto con el museo para facilitarnos datos y mucha documentación de la vida de esta singular mujer, que siempre escondió su faceta de modelo, por ser una profesión vergonzante en la España de la primera mitad del siglo XX.

O como la de la conocida desde tiempo inmemorial -por una inscripción en el reverso del marco- como Señora Carraquirre, que ha pasado, tras una concienzuda investigación a tener nombre y apellidos, Saturnina Moso Villanueva, esposa de Nazario Carriquiri, ambos partidarios de Isabel II contra el regente Espartero, y que había sido retratada magistralmente por el pintor sevillano Antonio María Esquivel. 
a debate Patrimonio, turismo y género. Estrategias para integrar la perspectiva de género en el patrimonio histórico

| coordinan Margarita M. Birriel Salcedo, Carmen Rísquez Cuenca

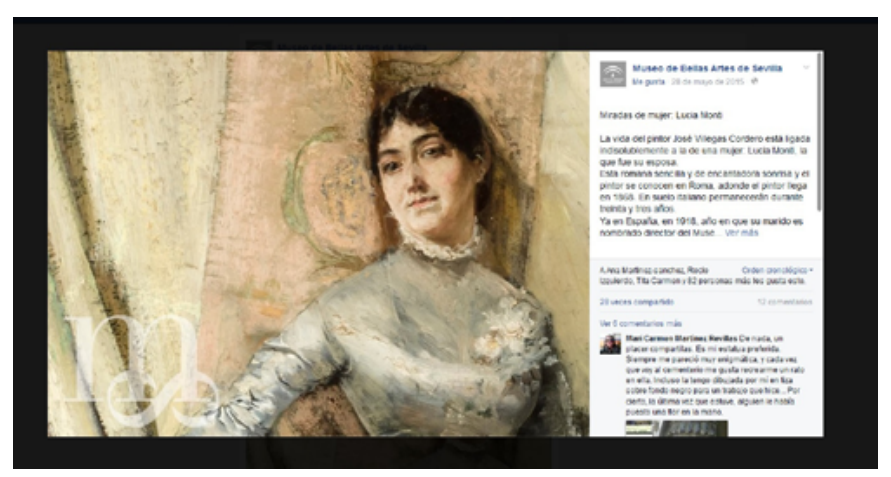

Miradas de mujer: Lucia Monti

Otra de las historias más apasionantes, y de gran repercusión, ha sido la de la italiana Lucia Monti ${ }^{2}$, esposa del pintor José Villegas, de familia de artistas, y donante de la mayor parte de la obra de su marido que se conserva hoy en día en el museo. Para ilustrar su vida sacamos a la luz parte de una rara entrevista que se le hizo en el tiempo en que el pintor sevillano era director del Museo del Prado de Madrid. La publicación de su semblanza en nuestra página de Facebook suscitó comentarios de personas sorprendidas por su desconocimiento absoluto de esta mujer gracias a la cual el museo contaba con importantes obras del pintor.

Una de las historias más curiosas ha sido la de Hilda Webb, retratada en varias obras que se conservan en el museo por su marido, Thomas Harris, que, aparte de pintor y afamado coleccionista y estudioso de Goya, había sido espía del MI-5, el servicio secreto británico, durante la Segunda Guerra Mundial. Las extrañas circunstancias en las que murió el artista en la isla de Mallorca en 1964, con ella como único testigo, quedaron para siempre en suspense.

Hasta ahora han sido muchas las historias de mujeres recuperadas del olvido, intentando con esta sección paliar el daño, el silencio o la omisión a la que se las ha sometido a lo largo de los siglos. Reyes Lallena, Irene Jiménez, Rosalía Paul Erné, Juana Garrigues o María Roy, por citar algunas de ellas, e incluso algunas otras visiones poéticas, como la de la mujer sevillana a través de los ojos de los viajeros románticos, o la figura de

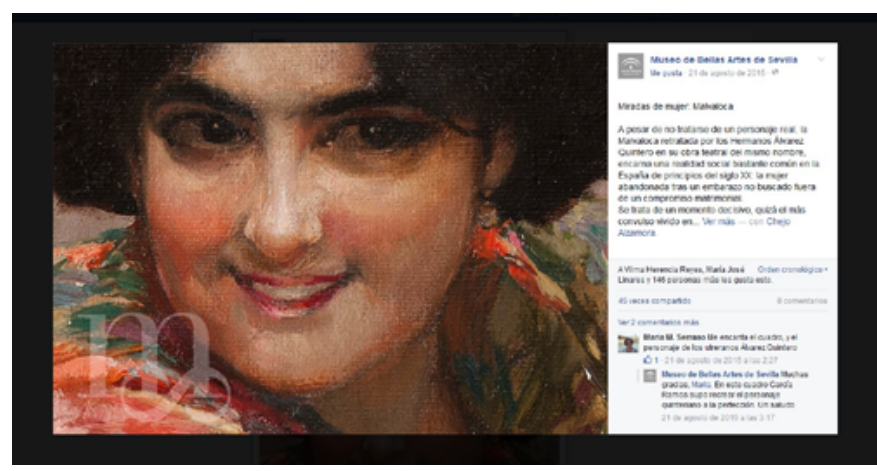

Miradas de mujer: Malvaloca

Malvaloca ${ }^{3}$, personaje de origen literario, pero fiel reflejo de la Andalucía de principios del siglo XX, bajo el estereotipo de mujer abandonada por el hombre al quedar embarazada y estigmatizada. La acogida por parte de los seguidores de Facebook de las historias de muchas de ellas ha sido espectacular. Continuar en esta línea, con las investigaciones, es fundamental para seguir arrojando datos a estas biografías oscuras de mujeres que nadie se preocupó nunca de recuperar hasta ahora. Otras muchas, desgraciadamente, de las que no conservamos ningún dato que nos sirva como punto de partida, quedarán para siempre relegadas al olvido y al más absoluto anonimato.

También cada 8 de marzo nos sumamos al Día de la Mujer Trabajadora con una publicación o una serie de ellas en torno al tema de la mujer y el trabajo. En 2015 la serie de posts relacionados con la creación de la obra Las cigarreras, de Gonzalo Bilbao, fue todo un éxito. Durante los cuatro días previos a la efemérides contamos cómo el pintor fraguó la obra durante años, y la convirtió, por propia convicción, en estandarte de la crítica social de la precaria situación de la cigarrera, y de la mujer obrera en general, por la que el artista sentía fascinación.

En este punto es necesario incidir en el papel fundamental que han desempeñado hombres como Gonzalo Bilbao, concienciado con los problemas de la mujer proletaria, a la que convirtió en su modelo en numerosas ocasiones. Desde su posición de artista de reconoci- 
miento nacional, fue una pieza primordial para el público conocimiento de la discriminación, la falta de derechos y la precariedad de la vida laboral de la cigarrera sevillana, realizando ese lienzo portentoso y emblema de la crítica social ${ }^{4}$ que presentó en Madrid en 1915, y que hoy tenemos la suerte de conservar en el museo, donde una trabajadora amamanta a su bebé en pleno trabajo, sin descanso, y sin higiene. Quería poner así Gonzalo Bilbao de manifiesto la triste realidad de estas mujeres, que entraban a trabajar a muy temprana edad (por lo general a los 13 años); que no tenían límite de jubilación; cobraban la mitad del jornal masculino en la misma fábrica; no tenían seguros por enfermedad, viudedad, incapacidad o alumbramiento; $y$, como queda patente en el lienzo, su agotadora jornada laboral debía ser compaginada con sus obligaciones maternas.

Un escollo importante, y un capítulo nos tememos que insalvable, pero fruto del escaso aprecio que de ellas ha hecho siempre el mundo artístico, es la práctica inexistencia de nombres de mujer en la nómina de artistas presentes en el museo. Ante esta situación, nuestra única alternativa ha sido la de dar visibilidad a través de las redes sociales a las escasas obras que de ellas figuran en las colecciones. Las obras de Margherita Caffi,

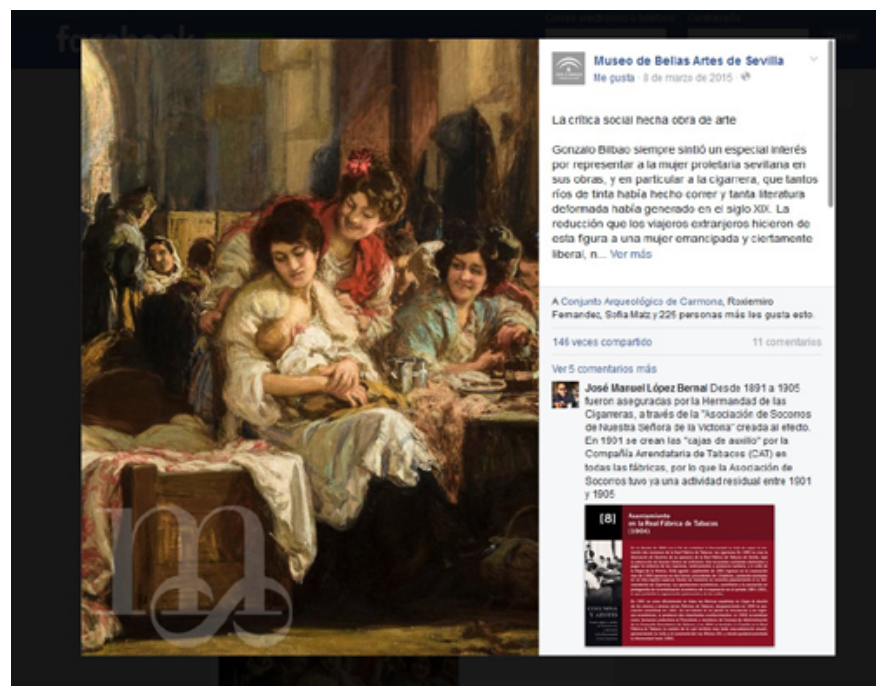

La crítica social hecha obra de arte
Magdalena Leroux, Carmen Jiménez o Luisa Roldán, conocida en la historia del arte como la Roldana, de manera algo peyorativa para soslayar su nombre de pila, han sido protagonistas de nuestras publicaciones de Facebook.

Mención especial merece el hecho de que son precisamente las mujeres la mayor audiencia de nuestra página en esta red social, al contrario que el porcentaje total de la misma, donde la mayor parte de usuarios son hombres. De 9.245 seguidores (diciembre, 2015), un 59\% son mujeres. También son ellas, con diferencia, las que más interacción crean en Facebook -a través de su participación con "me gusta" o comentarios-, subiendo el porcentaje femenino de participación al 66\%. En las otras redes en que estamos presentes, como Pinterest, Google+ y YouTube, que también nos ofrecen estadísticas, percibimos igualmente esta sustancial diferencia.

Para terminar, nos enorgullece que nuestro mensaje, de dar visibilidad a las mujeres vinculadas a la historia del arte, cale entre las personas que nos siguen y en muchas otras que, sin seguirnos, acaban siendo destinatarias de nuestras publicaciones. Es un anhelo que no pretende otra cosa que contribuir a la necesaria y justa igualdad de sexos y el dar su lugar a quien nuestra sociedad se lo ha arrebatado siempre: la mujer. Sabemos que una institución tan señera como el Museo de Bellas Artes de Sevilla puede hacer una gran labor en este sentido, en crear conciencia de igualdad, desde el privilegiado foro de las redes sociales. En este camino estamos, y seguiremos intentando que todos en algún momento veamos la vida con "miradas de mujer" 